\title{
Proton conductivity of perovskite types oxide $\mathrm{BaCe}_{1-\mathrm{x}} \mathrm{Y}_{\mathrm{x}} \mathrm{O}_{3-\delta}$
}

\author{
Yorinobu Katoh, Hiroshi Yamamura, Takenori Yokote, Katsuyoshi Kakinuma \\ Department of Material and Life Chemistry, Faculty of Engineering, \\ Kanagawa University \\ 3-27-1 Rokkakubashi, Kanagawa-ku, Yokohama 221-8686, Japan \\ Fax:81-45-413-9770, e-mail:r200670087@kanagawa-u.ac.jp
}

\begin{abstract}
Frequency dependences of dielectric constant $\left(\varepsilon_{\mathrm{r}}{ }^{\prime}\right)$, electrical conductivity and weight change were investigated for the perovskite-type oxide system $\mathrm{BaCe}_{1-\mathrm{x}} \mathrm{Y}_{\mathrm{x}} \mathrm{O}_{3-\delta}(\mathrm{x}=0.05 \sim 0.15)$, which is a typical proton conductor. The sample with $\mathrm{x}=0.15$ showed the maximum values in both proton conductivity and water content. Numerical calculation of frequency dependence of $\varepsilon_{\mathrm{r}}{ }^{\prime}$ clarified that the large $\varepsilon_{\mathrm{r}}{ }^{\prime}$ originates from the superimposition of both electrolyte-electrode interfacial and Debye-type polarizations. The Debye-type polarizations which are ascribed to the dopant-vacancy associates, $\left(\mathrm{Y}_{\mathrm{Ce}^{\prime}}{ }^{\prime}-\mathrm{V}_{\mathrm{O}}{ }^{\prime}\right)^{\prime}$ are depressed under wet $\mathrm{Ar}$ atmosphere. The decrease in the dipole showed the maximum at $\mathrm{x}=0.15$. Therefore, it can be speculated that the proton may occur according to the following equilibrium equation,
\end{abstract}

$\mathrm{H}_{2} \mathrm{O}+\mathrm{V}_{\mathrm{O}}{ }^{\prime \prime} \Leftrightarrow 2 \mathrm{H}^{*}+\mathrm{O}_{\mathrm{O}}{ }^{\times}$.

Key words: Proton conduction, Dielectric constant, Debye-type polarization, Oxygen vacancy, Defect associate

\section{Introduction}

The proton conductor can be applied to many devices such as hydrogen sensors, hydrogen fuel cells and hydrogen separation membranes. It is well known that $\mathrm{BaCeO}_{3}$-based perovskite oxides show proton conduction at elevated temperatures under $\mathrm{H}_{2}$ or $\mathrm{H}_{2} \mathrm{O}$ atmosphere, when $\mathrm{Ce}^{4+}$ was partially substituted by trivalent cations. ${ }^{1)-8)}$

The proton might be produced according to the following equilibrium equations,

$$
\begin{aligned}
& \left.\mathrm{H}_{2} \mathrm{O}+\mathrm{V}_{\mathrm{O}}{ }^{\cdots} \Leftrightarrow 2 \mathrm{H}^{\cdot}+\mathrm{O}_{\mathrm{O}} \times 7\right) \\
& \left.\mathrm{H}_{2} \mathrm{O}+\mathrm{V}_{\mathrm{O}}{ }^{\circ}+\mathrm{O}_{\mathrm{O}} \times{ }^{\times} \Leftrightarrow 2 \mathrm{OH}_{\mathrm{O}} \cdot 8\right)
\end{aligned}
$$

However, it has not been clear so far which mechanism is dominant for the appearance of proton conduction.

Recently, Yamamura et al. ${ }^{9-10)}$ have clarified by a computer simulation technique that the frequency dependence of $\varepsilon_{\mathrm{r}}{ }^{\prime}$ and $\varepsilon_{\mathrm{r}}{ }^{\prime \prime}$ in the Sm-doped $\mathrm{CeO}_{2}$ system, which is typical oxide-ion conductor, could be explained by the superimposition of electrolyte-electrode interfacial polarization and Debye-type polarization due to dopant-vacancy associate.

In the present study, the frequency dependence of $\varepsilon_{\mathrm{r}}{ }^{\prime}$ for $\mathrm{BaCe}_{1-\mathrm{x}} \mathrm{Y}_{\mathrm{x}} \mathrm{O}_{3-\delta}$, which is a typical proton conductor, were performed in order to clarify the proton-conduction mechanism, in addition to the measurements of electrical conductivity and thermogravimetry.

\section{Experimental procedures}

Powder samples of $\mathrm{BaCe}_{1-\mathrm{x}} \mathrm{Y}_{\mathrm{x}} \mathrm{O}_{3-\delta}$ were synthesized by a solid-state reaction, using $\mathrm{CeO}_{2}(99.99 \%$, High
Purity Chemicals), $\mathrm{BaCO}_{3}(99.9 \%$, Wako Pure Chemical Industries) and $\mathrm{Y}_{2} \mathrm{O}_{3}(99.9 \%$, High Purity Chemicals) as starting materials.

Weighed powders were wet ball-milled for $24 \mathrm{~h}$, using a milling pot made of synthetic resin and resin-coated balls, and ethanol as a dispersion reagent. The dried powder mixtures were calcined at $1273 \mathrm{~K}$ for $10 \mathrm{~h}$ in air. After sieving under $53 \mu \mathrm{m}$ in mesh size, the powder samples were uniaxially molded under the pressure of $5 \mathrm{MPa}$ and then subjected to rubber press under $200 \mathrm{MPa}$. The compacts thus obtained were sintered at $1673 \mathrm{~K}$ for $10 \mathrm{~h}$ in air.

The powdered samples were characterized by means of an X-ray diffraction (XRD) (model: Multi Flex, Rigaku) with monochromated $\mathrm{CuK} \alpha$ radiation. Lattice constant was determined from XRD peaks by a least square method, using Si powder as an external standard.

Dielectric constant $\left(\varepsilon_{\mathrm{r}}^{\prime}\right)$ was estimated as a function of frequency by the ac two-probe method in the temperature range from 573 to $1073 \mathrm{~K}$ under dry and wet Ar. The wet Ar atmosphere was obtained by flowing $\operatorname{Ar}\left(70 \mathrm{dm}^{3} / \mathrm{min}\right)$ saturated with water vapor at $313 \mathrm{~K}$. The impedance analyzer (4192A LF, Yokogawa-Hewlett-Packard) was used for the dielectric constant in the frequency range of $5 \mathrm{~Hz}$ to $13 \mathrm{MHz}$. The dimension of sintered disk for the ac conductivity measurements was $10 \mathrm{~mm}$ in diameter and $2 \mathrm{~mm}$ in thickness. For the all measurements, platinum electrode was attached to both sides of the specimen by firing at $1223 \mathrm{~K}$ for $30 \mathrm{~min}$ in air. Kaleida Graph (Synergy Software) was used for the numerical calculation of the dielectric parameters. 
3. Results and Discussion

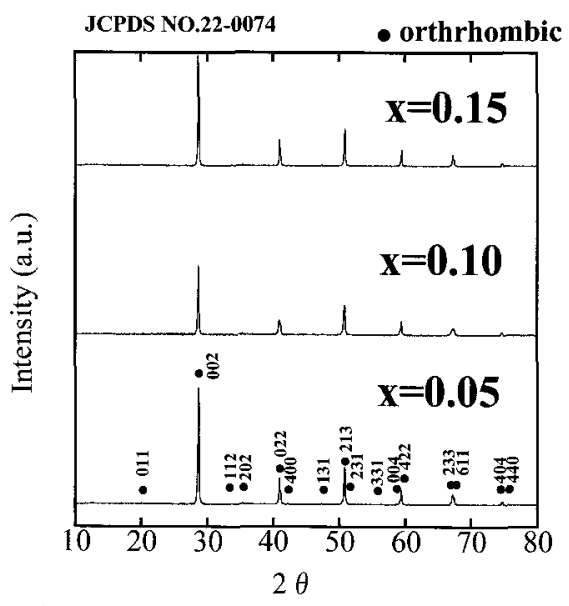

Fig. 1 XRD patterns of

$\mathrm{Ba}\left(\mathrm{Ce}_{1-\mathrm{x}} \mathrm{Y}_{\mathrm{x}}\right) \mathrm{O}_{3-\delta}(\mathrm{X}=0.05 \sim 0.15)$ systems

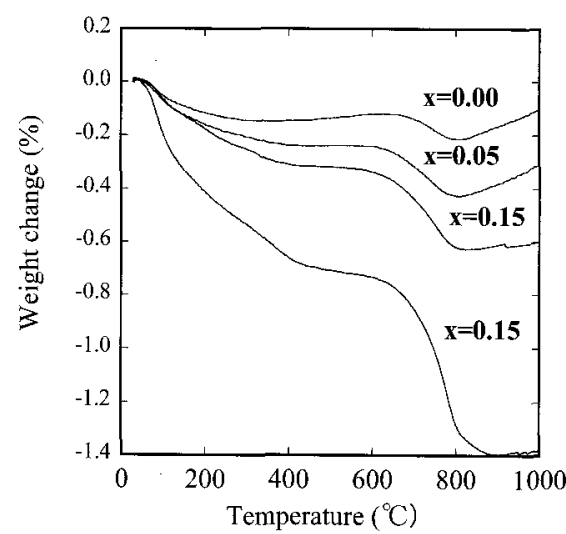

Fig.2 Relationship between weight change and temperature for $\mathrm{Ba}\left(\mathrm{Ce}_{1-x} \mathrm{Y}_{x}\right) \mathrm{O}_{3-\delta}$

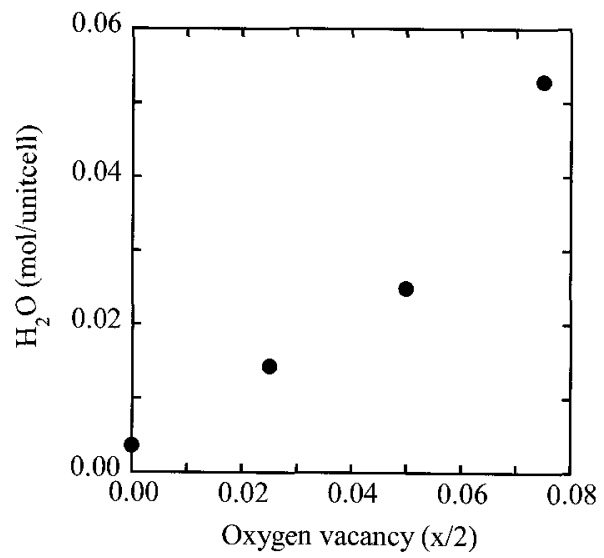

Fig.3 Relationship between oxygen vacancy and absorption water.

Figure 1 shows XRD patterns of $\mathrm{BaCe}_{1-\mathrm{x}} \mathrm{Y}_{\mathrm{x}} \mathrm{O}_{3-\delta}$ $(\mathrm{x}=0.05 \sim 0.15)$. It was confirmed that the present samples are single phases of perovskite-type oxide with orthorhombic symmetry.

Figure 2 shows TG-DTA curves. The all sample weight decreased with two steps. The first step at $573 \mathrm{~K}$ corresponds to desorption of water and the second one at $973 \mathrm{~K}$ dose to that of carbon dioxide. The weight loss due to the $\mathrm{H}_{2} \mathrm{O}$ desorption increased with increasing the concentration of oxygen vacancy, which can be controlled by the $\mathrm{Y}$ content in the $\mathrm{B}$ site. Figure 3 represents the amounts of desorbed $\mathrm{H}_{2} \mathrm{O}$ (mol/unit cell) in the temperature range from 473 to $773 \mathrm{~K}$ as a function of oxygen vacancy. This result means that $\mathrm{H}_{2} \mathrm{O}$ can be acceptable until one half of oxygen vacant sites.

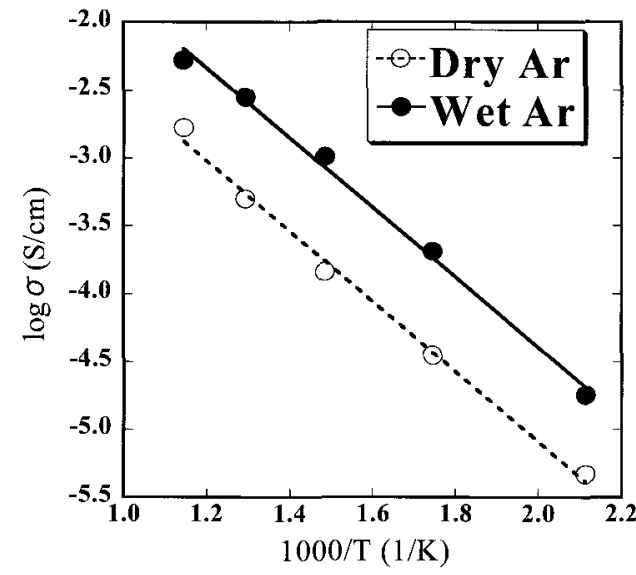

Fig.4 Arrhenius plots of conductivity in ac impedance measurement of $\mathrm{Ba}\left(\mathrm{Ce}_{0.9} \mathrm{Y}_{0.1}\right) \mathrm{O}_{3-\delta}$ systems.

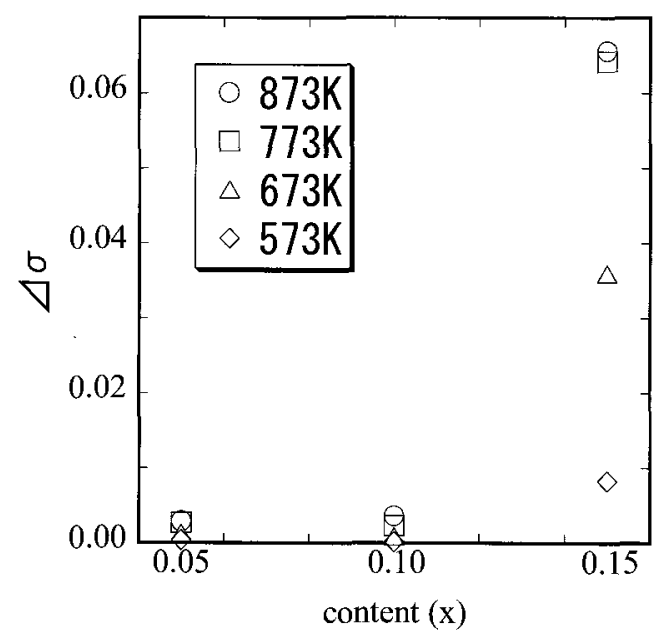

Fig. 5 Relationship between $\Delta \sigma$ and content $(\mathrm{x})$

Figure 4 represents the Arrhenius plots of electrical conductivity for $\mathrm{x}=0.1$ of the $\mathrm{BaCe}_{1-\mathrm{x}} \mathrm{Y}_{\mathrm{x}} \mathrm{O}_{3-\delta}$ system under dry- and wet- $\mathrm{Ar}$ atmosphere. The electrical conductivity in wet $\operatorname{Ar}\left(\sigma_{\text {wet }}\right)$ increased about one order in magnitude, compared with that in dry $\operatorname{Ar}\left(\sigma_{\text {dry }}\right)$. Here, we introduced $\Delta \sigma$ as a measure of magnitude of proton conduction, being defined by the following equation:

$$
\Delta \sigma=\sigma_{\text {wet }}-\sigma_{\text {dry }} \quad \text { (3) }
$$

Figure 4 represents the relationship between $\Delta \sigma$ and $\mathrm{x}$, where the compositional dependence of $\Delta \sigma$ shows a similar behavior with that in Fig.3, suggesting 
a)

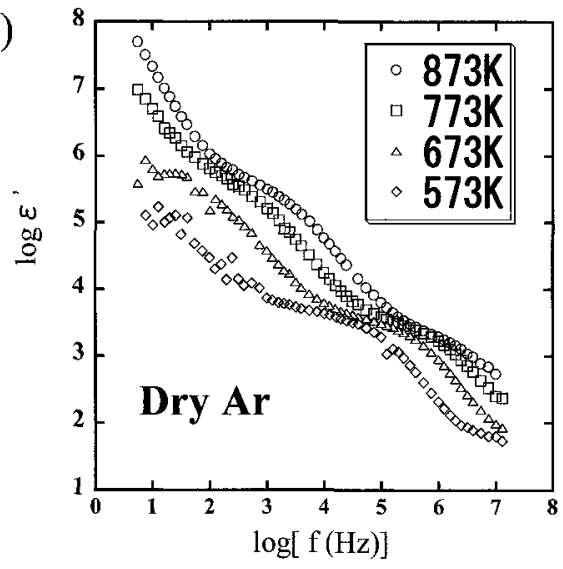

b)

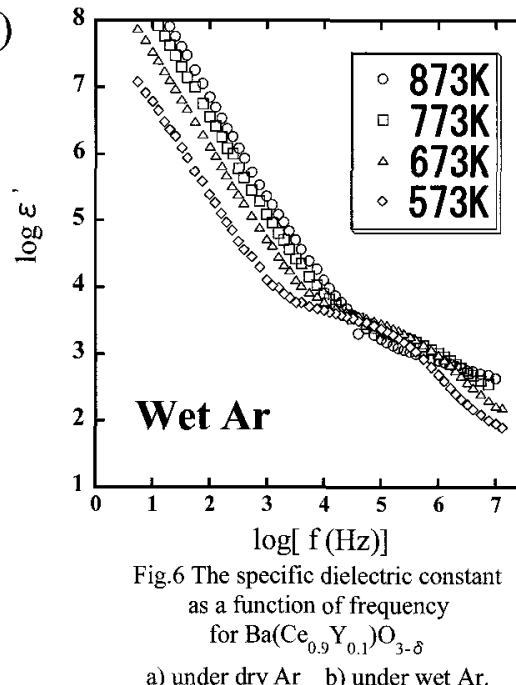

that the $\mathrm{H}_{2} \mathrm{O}$ in the crystal lattice has a close relation to the proton conduction.

Figure 6 show the frequency dependence of $\varepsilon_{\mathrm{r}}{ }^{\prime}$ for $\mathrm{x}=0.1$ under dry- and wet-Ar atmospheres, where two type dielectric relaxations were observed under dry-Ar atmospheres. It is speculated that the dielectric relaxation observed originate from the dopant-oxygen vacancy associate. The relaxation frequency observed under wet Ar was smaller than that under dry Ar.

The dielectric constant $\left(\varepsilon_{r}{ }^{\prime}\right)$ can be given as following equation:

$$
\varepsilon_{r}^{\prime}=\varepsilon_{r o s}+\frac{\varepsilon_{r 0}-\varepsilon_{r o s}}{1+\left(\omega \tau_{\mathrm{o}}\right)^{2}}+\frac{\varepsilon_{r}(0)}{\omega^{s}}
$$

where $\omega$ is the angular frequency $(=2 \pi \mathrm{f}), \tau_{0}$ is the dipole relaxation time, $\varepsilon_{\mathrm{r}}(0)$ and $\varepsilon_{\mathrm{r} \infty}$ are the low and high frequency limit of dielectric constant for the Debye-type polarization. $\varepsilon_{\mathrm{r}}(0)$, which is the proportional constant, is defined as a dielectric constant due to the interfacial polarization at low-frequency limit. Frequency exponent (s) is the constant parameter in order to generalize a function of frequency. The first two terms of the right side in eq.(4) represent the Debye-type dispersion, and the third term does the function which is proportional to the inverse of frequency. The detail explanation of eq.(4) is given elsewhere. ${ }^{9-10)}$

The typical dielectric parameters estimated are summarized in Table 1.
Table1 Computer simulation analysis $\varepsilon_{\mathrm{T}}(0)$ in dry Ar and wet Ar atmosphere at $573 \mathrm{~K}$.

\begin{tabular}{|c|c|c|c|}
\hline & $\mathrm{x}=0.05$ & $\mathrm{x}=0.10$ & $\mathrm{x}=0.15$ \\
\hline$\varepsilon_{\mathrm{r}}(0)$ (Dry Ar) & $1.6 \times 10^{3}$ & $2.3 \times 10^{3}$ & $2.3 \times 10^{3}$ \\
\hline$\varepsilon_{\mathrm{r}}(0)$ (Wet $\left.\mathrm{Ar}\right)$ & $2.9 \times 10^{2}$ & $7.9 \times 10^{2}$ & $8.0 \times 10^{2}$ \\
\hline
\end{tabular}

The Debye-type polarizations, which are ascribed to defect associates, $\left(\mathrm{Y}_{\mathrm{Ce}}{ }^{\prime}-\mathrm{V}_{\mathrm{O}}{ }^{\prime \prime}\right)^{\circ}$, were depressed under wet Ar atmosphere. And this decrease showed the maximum at $x=0.15$. Therefore, it can be speculated that the oxide-ion of $\mathrm{H}_{2} \mathrm{O}$ might be incorporated into the oxygen vacant site, resulting in the separation of proton from $\mathrm{H}_{2} \mathrm{O}$.

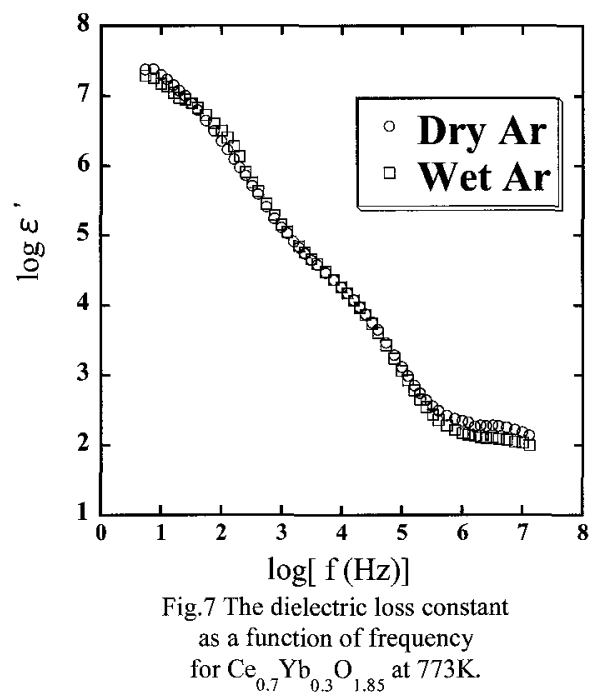

In the present study, we proposed that the proton conduction occurs due to the incorporation of $\mathrm{O}^{2-}$ of $\mathrm{H}_{2} \mathrm{O}$ into the oxygen vacancies, resulting in both the depression of the Debye-type dipole moment and the increase in the interfacial polarization. In order to confirm this speculation, we tried to investigate the dry or wet atmospheric effect on the dielectric properties of the oxygen deficient fluorite-type oxide $\mathrm{Ce}_{0.7} \mathrm{Yb}_{0.3} \mathrm{O}_{2-8}$, which is an oxide-ion conductor. ${ }^{11)}$ Figure 7 shows the frequency dependence of $\varepsilon_{\mathrm{r}}{ }^{\prime}$ at $773 \mathrm{~K}$ for $\mathrm{Ce}_{0.7} \mathrm{Yb}_{0.3} \mathrm{O}_{2-\delta}$ in dry and wet atmosphere. We could not observe such a difference in the $\varepsilon_{\mathrm{r}}{ }^{\prime}$ that was observed for the $\mathrm{BaCe}_{1-\mathrm{x}} \mathrm{Y}_{\mathrm{x}} \mathrm{O}_{3-\delta}$. This fact may strongly support that the depression in the Debye-type dipole moment and the increase in the interfacial polarization due to the incorporation of $\mathrm{H}_{2} \mathrm{O}$ in the lattice has a close relation with the proton conduction.

\section{Conclusion}

Frequency dependences of dielectric constant $\left(\varepsilon_{\mathrm{r}}{ }^{\prime}\right)$, electrical conductivity and water content were investigated for the perovskite-type oxide $\mathrm{BaCe}_{1-\mathrm{x}} \mathrm{Y}_{\mathrm{x}} \mathrm{O}_{3-}$ ${ }_{\delta}(x=0.05 \sim 0.15)$, which is a typical proton conductor. Proton conductivity and water content were maximum at $x=0.15$. The Debye-type polarizations which were ascribed to defect associates, $\left(\mathrm{Y}_{\mathrm{Ce}}{ }^{\prime}-\mathrm{V}_{\mathrm{O}}{ }^{\prime}\right)^{\prime}$ were depressed under wet Ar atmosphere. And this decrease was maximum at $\mathrm{x}=0.15$. 
Acknowledgements

This study was supported by the Scientific Frontier Research Project from the Ministry of Education, Science, Sport and Culture, Japan.

References

1) H. Iwahara, H. Uchida, K. Ono, K. Ogaki, J. Electrochem. Soc., 135 (1988) 529-533

2) F. Chen, P. Wang, O.T. Sorensen, G. Meng, D. Peng,

J. Matr. Chem., 7 (1997) 1533-1539

3) K.D. Kreuer, E. Schonherr, J. Maier, Solid State Ionics, 70/71 (1994) 278-284

4) T. Yajima, H. Iwahara, Solid State Ionics, 47 (1991) 117-124

5) K. Katahira, Y. Kohichi, T. Shimura, H. Iwahara, Solid State Ionics, 138 (2000) 91-98

6) T. Schober, Solid State Ionics, 145 (2001) 319-324

7) G. Ma, T. Shimura, H. Iwahara, Solid State Ionics, 110 (1998) 103-110

8) K. Takeuchi, C.-K. Loong, J.W. Richardson Jr., J.Guan, S.E. Dorris, U. Balachandran, Solid State Ionics $138(2000) 63-77$

9) H. Yamamura, S. Takeda, H. Nishino, K. Kakinuma, Y. Takeda, J. Ceram. Soc. Japan, 115 (2007) 23-27

10) H. Yamamura, S. Takeda, H. Nishino, K. Kakinuma,

J. Ceram. Soc. Japan, 115 (2007) 264-268

11)P.Sarken and P.S.Nicholsen, J.phys. chem. Solids, 50 (1989) 197

(Recieved December 9, 2007 ; Accepted September 1, 2008) 